André de Mello Galiano

Andréa Vettorassi ${ }^{2}$

Vera Lucia Navarro 3

\section{Trabalho, saúde e migração nos canaviais da região de Ribeirão Preto (SP), Brasil: o que percebem e sentem os jovens trabalhadores?*}

Labor, health, and migration in sugarcane plantations in the region of Ribeirão Preto, São Paulo State, Brazil: what do young workers perceive and feel?
${ }^{1}$ Graduado em Ciências Sociais. Mestre em Psicologia pela Faculdade de Filosofia, Ciências e Letras de Ribeirão Preto, Universidade de São Paulo, Ribeirão Preto, SP, Brasil.

2 Bacharel e mestre em Ciências Sociais. Doutora em Sociologia. Docente na Universidade de Ribeirão Preto (Unaerp) e docente e coordenadora acadêmica na Universidade de Franca (Unifran). Franca, SP, Brasil.

${ }^{3}$ Professora Associada da Faculdade de Filosofia, Ciências e Letras de Ribeirão Preto da Universidade de São Paulo. Ribeirão Preto, SP, Brasil.

\footnotetext{
*Artigo baseado na dissertação de mestrado de André de Mello Galiano intitulada Trabalho e migração: estudo com jovens trabalhadores no corte da cana-de-açúcar na região de Ribeirão Preto-SP, defendido em 02 de agosto de 2010 na Faculdade de Filosofia, Ciências e Letras de Ribeirão Preto da Universidade de São Paulo. Orientadora: Vera Lucia Navarro.

*Apresentado e premiado como melhor pôster no VI Congreso de la Asociación Latinoamericana de Sociología del Trabajo, realizado de 20 a 23 de abril de 2010 na cidade do México, publicado nos anais na forma de resumo.

Contato:

Vera Lucia Navarro

Universidade de São Paulo

Faculdade de Filosofia, Ciências e Letras de Ribeirão Preto

Avenida Bandeirantes, 3900 - Ribeirão

Preto, SP, Brasil

CEP: 14040-901

E-mail:

vnavarro@usp.br

Agência financiadora: Coordenação de Aperfeiçoamento de Pessoal de Nível Superior (Capes). Bolsa de Mestrado pelo Programa de Demanda Social (DS).
}

Recebido: 15/02/2011

Revisado: 12/03/2012

Aprovado: 19/03/2012

\section{Resumo}

A migração de jovens do nordeste brasileiro em busca de emprego na região Sudeste é historicamente recorrente. Este estudo objetivou compreender como jovens trabalhadores foram atraídos para o corte de cana-de-açúcar na região de Ribeirão Preto (SP) e conhecer como percebiam suas condições de trabalho e suas repercussões em sua saúde. Na pesquisa, de abordagem qualitativa, foram entrevistados 14 trabalhadores migrantes do Maranhão, de ambos os sexos, com idades entre 18 e 24 anos, entre julho de 2008 e maio de 2009. Os relatos obtidos indicaram que a migração dos jovens trabalhadores em busca de trabalho não foi uma opção, mas a única alternativa frente à realidade na região de origem. Revelaram sentimento de frustração quando perceberam que o trabalho real era bem diferente do imaginado. Os jovens apresentaram desesperança quanto às suas perspectivas de futuro e demonstraram preocupação com as possíveis consequências para sua saúde. Apesar de explicitar desapontamento com a realidade, manifestaram intenção de retorno para as lavouras da cana em outras safras, mostrando conformismo com sua realidade social. O estudo possibilitou aprofundar conhecimentos acerca da exploração da força de trabalho empregada na cultura da cana-de-açúcar na maior região produtora do país, mostrando que os trabalhadores percebem como precárias e desgastantes as condições a que são submetidos.

Palavras-chave: trabalho rural; migração; cana-de-açúcar; trabalho e saúde; agroindústria canavieira.

\begin{abstract}
The migration of young people from the Northeast to the Southeast of Brazil searching for employment is historically recurrent. The purpose of the present study was to understand how this young people are attracted to the sugarcane harvesting in the region of Ribeirão Preto, São Paulo State, and to learn how they become aware of their working conditions and the impact of these conditions on their health. For this qualitative research, 14 female and male workers between 18 and 24 years of age, who had migrated from the State of Maranhão, were interviewed between July 2008 and May 2009. According to their reports, young people had no other alternative but to migrate to find a job, due to the harsh reality of the region where they came from. The workers revealed frustration as they realized the jobs they found were not what they had expected. They also expressed hopelessness regarding their future and worries about health being damaged due to the type of work. Although they expressed disappointment with this reality, they intended to return to the sugarcane plantations in the next harvests, demonstrating their conformism to their social reality. This study allowed us to deepen our knowledge on labor force exploitation in sugarcane plantations in the largest producing region of the country, and showed that workers perceive the precariousness and stressfulness of the conditions they experience.
\end{abstract}

Keywords: rural work; migration; sugarcane; work and health; agribusiness. 


\section{Introdução}

\section{A problemática da pesquisa}

No Brasil, de acordo com Pochmann (2000), no final do século XX, os jovens com idade entre 15 e 24 anos $^{3}$ representavam cerca de $20 \%$ da população brasileira, dos quais $80 \%$ se encontravam no meio urbano e $20 \%$, no meio rural. Ocorreu, naquele período, crescente aumento do movimento migratório nacional de jovens desta faixa etária que saem, em sua maioria, das regiões Norte e Nordeste do Brasil para os estados da região Sudeste (POCHMANN, 2000). De acordo com Antunes (1999), quanto maior é o crescimento de nossa sociedade, menor é sua capacidade de incorporação de jovens no mercado de trabalho, em que encontramos a seguinte situação: não há empregos para todos aqueles que dele necessitam e os que estão empregados, em geral, trabalham muito e sempre temem o desemprego.

Dada a discrepância social que permeia o nosso país, a diferença socioeconômica que se aplica aos jovens traz consigo, de um lado, a luta pela escolha profissional e, de outro, a marginalização e a consequente exclusão social dos mais desprovidos ou menos abastados que, em virtude da pobreza, tendem a desistir dos estudos para ajudar na manutenção de sua família. Logo, por não encontrarem trabalho em sua região, a migração acaba sendo a única alternativa para se inserirem no mercado de trabalho. A saída de trabalhadores de estados como Ceará, Bahia, Piauí e Maranhão, dentre outros, em busca de emprego na região Sudeste jamais cessou, assim como a presença de jovens entre estes migrantes. Os que migram para o corte da cana no interior do estado de São Paulo são exemplos desta realidade (SILVA, 2007).

Estudiosa do trabalho e das condições de vida destes migrantes, Silva (2006) relatou que muitos deles vivem em suas regiões de origem como camponeses, outros são rendeiros e outros já vivem nas periferias das cidades na condição de proletários. Estas condições de vida nas regiões de origem também foram observadas por Vettorassi (2010) no interior do Piauí. A migração é essencialmente masculina: enquanto os homens partem, as mulheres ficam. Entretanto, muitos trazem suas esposas para o auxílio no trabalho doméstico. Também é perceptível, de acordo com pesquisas de campo de Vettorassi (2010), que há um número crescente de migração feminina para serviços domésticos e em fábricas da indústria têxtil no interior paulista. Em se tratando especificamente do trabalho na colheita de cana, os jovens migrantes do sexo masculino são os trabalhadores preferidos pelas usinas. De acordo com Novaes (2007):

\begin{abstract}
Os trabalhadores que chegam do Nordeste possuem um perfil condizente com o que se precisa hoje para o corte manual. Segundo eles próprios, por terem sido, desde crianças, socializados no árduo e duro trabalho da agricultura na sua região de origem, o trabalho no canavial não os assusta. Além disso, segundo relato dos técnicos das usinas, são preferidos pelos usineiros por serem mais dedicados ao trabalho e gratos aos empregadores pela oportunidade do emprego, inexistentes em suas regiões. A necessidade premente de ganhar dinheiro, para assegurar a subsistência da família distante, tem funcionado como um freio que os torna mais tolerantes com descumprimentos de leis trabalhistas, com as injustiças e as distorções que ocorrem nas medições feitas pelo fiscal de turma em sua produção diária no corte da cana. (NOVAES, 2007, p. 171)
\end{abstract}

Segundo Rosa (2009), a questão do sexo e da juventude está diretamente relacionada às exigências feitas pelas usinas para se contratar trabalhadores para o corte da cana, porém, são também critérios importantes:

[...] "boa conduta" ou subordinação, a capacidade de manter a assiduidade, e consequentemente a saúde, durante toda a safra e a produtividade. Sem dificuldade, pode-se afirmar que os dois últimos critérios são mais facilmente alcançados por pessoas jovens e do sexo masculino, mesmo havendo exceções. (ROSA, 2009, p. 93)

É da realidade destes trabalhadores que iremos tratar neste artigo, baseados em pesquisa que teve por objetivo compreender como jovens trabalhadores foram atraídos para o corte de cana-de-açúcar na região de Ribeirão Preto (SP) e conhecer como percebiam suas condições de trabalho e suas repercussões em sua saúde. Ao se delimitar o objeto desta pesquisa na migração e no trabalho de jovens com idade entre 18 e 24 anos, o estudo busca contribuir com outros que vêm registrando mudanças no perfil destes trabalhadores. Observou-se uma tendência na contratação de trabalhadores mais jovens, com mais vigor físico e, de preferência, do sexo masculino.

\section{O universo empírico da pesquisa}

Localizada no nordeste do estado de São Paulo, a região de Ribeirão Preto é considerada o principal polo sucroalcooleiro do mundo. Isto porque, além de produzir mais de 35\% do álcool do país, também é o centro do conhecimento mundial na área. Segundo o Instituto de Economia Agrícola (2008), as 82 cidades da região abrigam cerca de 40 usinas e mais de 300 empresas de equipamentos agroindustriais.

\footnotetext{
${ }^{3}$ No Brasil, devido à precocidade de ingresso no mercado de trabalho, entende-se por população juvenil os adolescentes entre 15 e 18 anos de idade e o jovem adulto entre 19 e 24 anos de idade (Pochmann, 2000).
} 
Ribeirão Preto é economicamente uma região bastante diversificada, com setor industrial moderno, atividades de comércio e serviços bem desenvolvidos e produção agrária realizada em bases capitalistas. O polo de maior desenvolvimento da região é representado pelo setor agrário, que possui como principal fonte produtiva a agroindústria, com destaque para a açucareira (SILVA, 1999).

Dado o intenso crescimento de sua produção, em 1990, a região de Ribeirão Preto foi apresentada ao Brasil como a "Califórnia brasileira". A reportagem de uma grande emissora de televisão informou à época que, graças aos empresários da indústria do açúcar e do álcool, esta seria uma região moderna, rica, sem problemas e pobreza, incentivando desta forma a migração dos trabalhadores rurais para aquelas cercanias (SCOPINHO, 2003). Segundo Thomás Jr. (2002), nesta mesma década, a região de Ribeirão Preto já se destacava pela produção de $40 \%$ da cana-de-açúcar em todo o Estado de São Paulo.

Pradópolis, município distante cerca de $30 \mathrm{~km}$ de Ribeirão, foi escolhida para a realização desta pesquisa por abrigar crescente número de migrantes vindos do interior do estado do Maranhão nos últimos anos (FACIOLI; PERES, 2007) e por abrigar uma das maiores usinas produtoras de cana-de-açúcar da região.

Com população aproximada de 16.000 habitantes, a cidade recebe todos os anos trabalhadores migrantes para o corte manual da cana-de-açúcar; o município conta com mais de 15 mil hectares (ha) de cultivos de cana e produziu, em 2007, cerca de $85 \mathrm{t}$ de cana/ha. Segundo o Instituto Brasileiro de Geografia e Estatística (2009), 22\% de seus habitantes são pobres e sua população cresceu cerca de $40 \%$ nos últimos dez anos.

\section{Métodos}

A pesquisa, de abordagem qualitativa, foi realizada com trabalhadores rurais empregados no corte da cana-de-açúcar na região de Ribeirão Preto (SP). Ao todo foram entrevistados 14 trabalhadores, sendo 13 do sexo masculino e 1 do sexo feminino, com idades entre 18 a 24 anos, dos quais três eram casados e quatro tinham filhos. Todos eram alfabetizados, 12 tinham o Ensino Fundamental incompleto e apenas dois concluíram o Ensino Médio. Todos os 14 entrevistados afirmaram ser esta sua primeira experiência de trabalho no corte da cana-de-açúcar. Todos eram migrantes do estado do Maranhão, das cidades de Codó, Chapadinha do Maranhão e Timbiras. Minayo (1994) afirmou que a pesquisa de cunho qualitativo possui a característi- ca de não privilegiar o critério numérico, mas sim a capacidade de refletir a totalidade do fenômeno nas suas múltiplas dimensões. Isto explica o fato de a quantidade de sujeitos selecionados para a pesquisa não corresponder a um critério preponderante, importando de fato a qualidade e a quantidade de informações que podem ser obtidas dos informantes selecionados.

Antecedeu o trabalho de campo uma visita à localidade em que residiam os trabalhadores. Nesta ocasião, foram realizadas entrevistas exploratórias, que serviram como pré-teste de validação, com três trabalhadores apresentados ao pesquisador por uma ex-cortadora de cana, indicada por um outro estudioso da temática. Tais entrevistas tiveram o objetivo de colher ideias e informações acerca do objeto de estudo e subsídios para elaboração do roteiro final de entrevistas. No trabalho de campo propriamente dito, o contato com os trabalhadores-alvo da pesquisa foi feito de maneira direta pelo primeiro autor deste artigo, em um bairro da periferia da cidade de Pradópolis (SP), cidade localizada a $50 \mathrm{~km}$ de Ribeirão Preto (SP).

A partir do primeiro trabalhador entrevistado, os outros foram sendo indicados sucessivamente um pelo outro. Tal metodologia de recrutamento é conhecida como indicação sucessiva, técnica em cadeias ou, ainda, bola de neve (snowball). Biernacki e Waldorf (1981) afirmam que tal técnica possibilita o encontro de pessoas com características definidas, de acordo com os pressupostos e as necessidades da pesquisa.

A principal técnica de coleta de dados foi a entrevista semiestruturada. Para tanto, desenvolveu-se um roteiro que combina perguntas fechadas (ou estruturadas) e abertas. O roteiro semiestruturado foi composto pela combinação de sete questões fechadas e 11 questões abertas. As questões fechadas tinham como objetivo levantar dados sociais, como origem, cor da pele, estado civil, se tinham filhos, escolaridade e rendimento financeiro familiar. Já as questões abertas traziam uma abordagem mais subjetiva que visava verificar a opinião destes entrevistados acerca dos motivos de sua migração, trazendo informações a respeito do processo de contratação, da viagem, de suas primeiras impressões sobre o trabalho em questão, da rotina no campo, das formas de remuneração, do uso do tempo livre e das condições de saúde e moradia.

As entrevistas foram gravadas e tiveram duração média de quarenta minutos. Todas foram realizadas na residência dos trabalhadores, entre os meses de julho de 2008 e maio de 2009. Após a transcrição das entrevistas, seguida da releitura do material, foram identificadas as ideias centrais, juntamente com as estruturas de relevância e os momentos-chave, 
utilizando o conceito de representação social como categoria geral, que tem fundamentado o trabalho de campo na pesquisa qualitativa (MINAYO, 1994). Os entrevistados citados no corpo deste texto serão identificados pela letra "E", seguida do numeral correspondente à ordem das entrevistas.

Foi apresentado aos entrevistados o Termo de Consentimento Livre e Esclarecido, que informava sobre a temática da pesquisa, seus objetivos e o compromisso ético. Esta pesquisa foi aprovada pelo Comitê de Ética em Pesquisa da Faculdade de Filosofia, Ciências e Letras de Ribeirão Preto, da Universidade de São Paulo, de acordo com o Processo CEP-FFCLRP USP $n^{\circ}$ 375/2008.

\section{Resultados e discussão}

\section{Fatores motivacionais para o processo migratório}

As condições de vida na região de origem dos jovens entrevistados, de acordo com seus depoimentos, mostram-se preocupantes. A Tabela 1 apresenta os principais motivos relatados pelos jovens em questão que os incentivaram à migração em busca de trabalho. Destaca-se aqui a intenção de ajuda à família e a escassez de emprego em sua região.

A ausência de perspectivas de futuro é outro dado importante que se manifestou em dez dos entrevistados, tornando a decisão migratória uma das poucas alternativas disponíveis para a mudança da realidade destes jovens.

Quando questionados acerca das motivações pela decisão migratória e pelo trabalho na indústria canavieira, a maior parte dos entrevistados (10 trabalhadores) afirmou que a falta de empregos em sua região é uma das principais razões. A opção pelo trabalho no corte da cana também recebeu influência direta ou indireta de amigos ou familiares que já haviam tido alguma experiência nas lavouras do interior de São Paulo (12 trabalhadores), que muitas vezes retornavam das safras com bens de consumo adquiridos no período da realização deste trabalho, como aparelhos de DVD, leitores portáteis de músicas etc. Outro fator de grande influência foi a possibilidade de envio de recursos financeiros aos familiares que permaneceram em casa. Todos os entrevistados afirmavam que o faziam, fortalecendo, desta forma, a ideia expressa por metade deles de uma melhor remuneração deste trabalho no interior paulista decorrente de experiências anteriores, suas ou de seus conhecidos da região do Maranhão.

Em função da pesquisa ter como foco os trabalhadores com idade variante entre 18 e 24 anos, onze deles se deparavam com seu primeiro emprego. Para estes, muitas vezes, a única alternativa para se obter algum rendimento financeiro era a da migração, dada a dificuldade ou a inexistência de trabalho assalariado em sua região, corroborando o estudo de Alves (2007), que identifica aqueles trabalhadores como " [...] homens jovens, que têm como único objetivo ganhar dinheiro para sustentar suas famílias, que ficam distantes" (p. 21), bem como o de Silva (2002), visto que a maioria dos entrevistados revelou que a migração em busca de trabalho não é uma simples escolha, mas uma necessidade premente:
A ausência de outras alternativas, além da omissão do Estado, tem criado as bases para um deslocamento espacial e temporal incessante. [...] São vidas definidas por um vaivém perene, por uma eterna migração forçada que lhes impinge a marca de um destino social. (SILVA, 2002, p. 31)

Tabela 1 Categorias temáticas das verbalizações de trabalhadores migrantes $(\mathrm{N}=14)$ empregados nas lavouras de cana-de-açúcar na cidade de Pradópolis (SP) que caracterizam os fatores que influenciaram sua decisão pela migração, 2008-2009

\begin{tabular}{lc}
\hline \multicolumn{1}{c}{ Categorias } & Número de respostas \\
\hline Ausência de empregos e perspectivas & 10 \\
Influência dos amigos / familiares & 12 \\
Ajuda à família & 14 \\
Anseio pela aquisição de roupas / produtos eletrônicos & 5 \\
Melhor remuneração em São Paulo & 7 \\
\hline
\end{tabular}




\section{Tornando-se migrante}

Deixar para trás os seus familiares e amigos é também deixar parte de sua base de formação como ser social, sua segurança e, segundo um dos entrevistados, "é deixar um pedaço de você" (E4).

No Maranhão deixei minha família inteira, mas trouxe minha mulher. Nós somos em 17 irmãos, são três homens e 14 mulheres, todos filhos do mesmo pai. (E5)

Tenho um moleque lá. Vim pra cá pra poder manter ele vivo. [...] Eu morava com minha avó, então eu já ficava longe dos pais, mas nunca tinha saído do Maranhão. (E8)

Segundo os relatos dos sujeitos da pesquisa, os primeiros contatos com os contratantes para o trabalho no corte da cana são realizados ainda no Maranhão, através da indicação de trabalhadores sazonais já empregados na indústria canavieira. A figura do intermediador, ou chamado "gato", é papel central no processo de migração e contratação. Ele seleciona os pretendentes ao trabalho na cana e organiza as lotações dos ônibus que os transportarão até o interior paulista. Este transporte tem duração média de três a cinco dias e é feito sem quaisquer contrato e garantia formal de que este sujeito será contratado.

Bom, o cara que faz a lotação já é acostumado a vir a trabalhar e voltar, vem e volta após a safra. Vai lá no Maranhão e faz a lotação, mas ele não faz com contrato assinado, faz a lotação pra ganhar uma porcentagem também. Ele traz e chega aqui. Como ele já conhece vários fiscais, aí ele só indica, cem, cinquenta homens. Lá mesmo no Maranhão ele já sabe o quanto está precisando. O fiscal da usina manda fazer a lotação do ônibus, aí faz quatro, cinco lotação e traz. (E9)

Há dois estereótipos contraditórios da comunidade rural e seus aspectos identitários: ela é retratada como estável, conservadora, imutável (BIANCO, 1987), no entanto, na sociedade agrária há indivíduos em movimento, tanto social, quanto geográfico. O fluxo de pessoal pode resultar de nascimentos, casamentos, adoções, divórcios e mortes (passagens de status relatadas em etnografias, mas raramente incorporadas às análises de processos sociais), como também pode resultar de movimentos migratórios de blocos e pequenas parcelas da população.

Na tentativa de construir um trabalho multifacetado, bem como de identificar as mudanças e os fluxos numa aparente estabilidade estrutural, Vettorassi (2010) realizou, em um ônibus clandestino, uma viagem de volta às cidades nordestinas feita por homens, mulheres e crianças que viviam e trabalhavam na capital de São Paulo e em cidades da região de Ribeirão Preto (SP). Em sua tese de doutorado e em um videodocumentário, ${ }^{4}$ Vettorassi relatou tempos e espaços muito particulares, numa longa viagem que carregava tensão e, ao mesmo tempo, a feliz expectativa de voltar para casa. $\mathrm{O}$ espaço é a rede social, a base onde a ação coletiva é criada. O processo de formação de classe tem uma dinâmica dupla: por um lado, envolve as relações sociais de largo alcance e que ligam os membros de uma classe por diferentes lugares. Por outro lado, a construção de classes também exige laços densos e a construção de identidades solidárias, e isso é extraído da comunidade. Quando observado o anseio pela volta, é perceptível que a comunidade ("liga dos comuns”) mais sentida pelos migrantes nordestinos está em suas terras de origem. Nas cidades paulistas, estes grupos vivenciam a construção de uma identidade relacionada ao trabalho, que é cotidianamente almejado, procurado e conquistado onde quer que ele esteja não só para suprir necessidades físicas, mas também para a satisfação de necessidades simbólicas, mesmo quando este trabalho é insalubre e implica em malefícios para a saúde (VETTORASSI, 2010).

Não é a migração em si que define a identidade destes homens e mulheres, mas sim os aspectos simbólicos que edificam suas identidades em torno do trabalho. Em busca deste trabalho, homens e mulheres definem e redefinem redes muito bem articuladas que permitem, por exemplo, a organização dos ônibus clandestinos que possibilitam idas e vindas menos onerosas. Entretanto, as condições de transporte são precárias. Vettorassi (2010) relata que por quatro vezes o ônibus clandestino em que viajava quebrou e, em uma delas, perdeu o freio traseiro. As piores estradas e rodovias são priorizadas pelos motoristas, pois eles evitam fiscalizações e policiamento. Há excesso de bagagens e de passageiros. São também perceptíveis estas características nos relatos dos jovens migrantes entrevistados:

\footnotetext{
O ônibus não é de empresa não, é clandestino, assim. Traz gente e leva, [...] E vem direto pra cá. Chegamos aqui em três dias. (E1)

Tem vez que nem dá pra almoçar e jantar. A gente come no "busio" [ônibus] mesmo. Lá do Maranhão, de Chapadinha, pra vir pra cá, nós paramos só uma vez, só um dia pra almoçar. Foram 42 horas de viagem. Saímos do Maranhão às seis horas da manhã, nós paramos só uma vez e foi por 30 minutos. Só pra ir usar banheiro e pegar uma merenda. (E9)
} 
Para além dos aspectos econômicos que redefinem a vida dos migrantes nordestinos em São Paulo, é perceptível que, especialmente ao longo da viagem realizada por Vettorassi (2010), entre os trabalhadores há uma contínua desvalorização do trabalho no corte da cana. Muitos dos passageiros do ônibus clandestino eram ex-cortadores de cana, hoje pedreiros e mecânicos convictos de que não há sofrimento maior que o do cortador de cana. É por isso que muitos procuram o setor sucroalcooleiro quando todas as outras opções já estão esgotadas, e há até mesmo uma hierarquia de status entre os outros trabalhadores frente aos passageiros cortadores de cana entrevistados. A pesquisa de campo e as entrevistas realizadas por Vettorassi (2010) com estes homens e mulheres levam a crer que o trabalho no corte da cana vem sofrendo escassez, mas há um sentimento de pertencimento e necessidade muito maior com o trabalho em si do que com o trabalho rural, independentemente de qual trabalho seja e onde ele esteja, porque o trabalho rural nos locais de origem está condenado há décadas e é desvalorizado pelas gerações futuras.

A viagem com estes trabalhadores, ansiosos pela volta à sua terra natal, atenta para a fluidez de suas condições de trabalho, para as estratégias de sobrevivência e, consequentemente, para as suas redes sociais e as condições de trabalho e moradia nos locais de destino (VETTORASSI, 2010).

\section{Contratação e moradia}

Ao chegarem à cidade de Pradópolis (SP), os viajantes entrevistados foram encaminhados pelo chamado "turmeiro" às suas moradias, em geral localizadas em bairros da periferia da cidade, para aguardarem o processo de seleção pelas usinas.

O processo de seleção dos trabalhadores, para a efetiva contratação pelas usinas, inclui uma série de exames médicos, como os de capacitação física, cardiológicos e oftalmológicos. Se "aprovado" nos exames, o trabalhador é contratado por três meses de experiência, podendo ser ou não efetivado após este período:

Depois que chega na cidade é que eles vão explicar como é que é o serviço. Tem um cara que fica aqui, que é o fiscal, o turmeiro, que toma conta das turmas. Ele leva as carteiras [de trabalho] pra usina. A partir daquele dia o cara vai fazer exames, e depois que passar dos exames é que vai assinar o contrato. Depois que assina o contrato, passam ainda 90 dias, e depois disso é que o cara está mesmo contratado. (E9)

Se você tiver qualquer problema, vai estalar a coluna e vai doer [...]. Fiz exame de sangue, fezes e urina... Se desse qualquer problema, eles não passariam a gente. (E1)

Tais relatos corroboram, desta forma, o estudo de Silva (1999), que retrata como a presença do médico é de caráter fundamental para a manutenção desta linha de produção:
A presença do médico não preenche apenas a função de providenciar a cura dos corpos doentes. Ele funciona como elemento fundamental na triagem dos corpos, mesmo antes deles serem postos em atividade. Os corpos chagásicos, os fracos, os velhos, os muito jovens, não vão para o corte. Destinam-se, por ordem médica, a outras funções: faxineiros, cozinheiros, membros das equipes de fogo, sinalizadores, ajudantes do interior da indústria. O saber médico recomenda, mediante testes ergométricos, psicológicos, físicos, a melhoria dos recursos humanos à disposição da usina para a consecução da formação de corpos bem treinados para o trabalho. (SILVA, 1999, p. 203)

Quando há incidência de faltas, ou frequente número de atestados médicos, ou, ainda, quando o trabalhador é desligado por razões de má conduta, existe a chamada "lista negra" que, segundo um dos entrevistados, circula entre as usinas para evitar a recontratação dos trabalhadores de "má conduta" ou menos produtivos, como demonstra Rosa (2009) em sua pesquisa. Esta situação gera diretamente preocupação e insegurança junto aos trabalhadores, como bem demonstra Seligmann-Silva (1994):

O cultivo da incerteza da desinformação e de ameaças explícitas de demissão, completa o sofrimento de quem ainda não se tornou desempregado. [...] A perda do trabalho é a perda da subsistência, tão mais grave, quanto maior for a pobreza. (SELIGMANN-SILVA, 1994, p. 35)

Quanto à moradia, os sujeitos do estudo foram divididos em turmas pelo "gato", sendo assim distribuídos em residências ou alojamentos com outros trabalhadores migrantes, propiciando maior rateio dos custos com moradia. As casas visitadas para a realização das entrevistas estavam localizadas em um bairro bastante carente, com baixa iluminação e apenas algumas ruas asfaltadas. Não possuíam muros nem lajes, o que, segundo um dos entrevistados (E3), aumentava consideravelmente o calor durante o dia e intensificava os eventuais frios da madrugada. Também foi notado que em muitos quintais havia o cultivo de hortas para consumo próprio. Segundo comentários da pessoa que intermediou os contatos com os entrevistados, grande parte dos moradores deste bairro era de trabalhadores rurais, em sua maioria migrantes de outros estados. Possuía localização na região periférica da cidade de Pradópolis (SP), próximo a uma das principais usinas de cana-de-açúcar da região.

As seis residências visitadas possuíam de um a dois quartos, uma sala, uma cozinha e um a dois banheiros, chegando a abrigar 18 moradores, que, dentro de suas possibilidades, organizavam seus espaços, distribuindo os finos colchões pelo chão da sala e até mesmo da cozinha. Os 14 entrevistados moravam em casas distintas divididas em dois bairros próximos e que recebem significativo número de migrantes maranhenses, como pudemos observar ao 
longo da pesquisa de campo. De acordo com Seligmann-Silva (1994), as condições de vida precárias de trabalhadores contribuem para o aumento da fadiga, da tensão e do esgotamento físico.

Fadiga e tensão também são produzidas por condições de vida precárias, como moradia inadequada, grande distância em relação ao local de trabalho e transportes coletivos insuficientes. O baixo nível salarial impede qualquer lazer, e distúrbios de saúde [...] também contribuem para levar ao esgotamento nervoso. (SELIGMANN-SILVA, 1994, p. 26)

Além das despesas pessoais com vestimentas, alimentação e lazer, jovens entrevistados possuem o compromisso do envio mensal de ajuda financeira aos seus familiares, o que nem sempre ocorre em todos os meses em virtude do alto custo de vida no interior de São Paulo. Algumas usinas forneciam cestas básicas apenas para os trabalhadores que atingiam as metas de produção, sendo esta muitas vezes convertida em um bônus em torno de sessenta reais junto ao seu salário, de acordo com informações obtidas no trabalho de campo (E9 e E12).

\section{Processo de trabalho e degradação da saúde}

Após serem aprovados nos exames médicos e contratados pela usina, estes jovens adentram nos canaviais e visam desbravar esta nova realidade, tendo assim o seu primeiro contato não apenas com o trabalho na cultura canavieira, como também com as agruras de uma atividade marcada por densa carga laboral. ${ }^{5}$ Os depoimentos e as percepções aqui registrados foram obtidos nos primeiros dias de trabalho com o corte ou o cultivo da cana-de-açúcar:

Comecei ontem, foi o primeiro dia. Primeiro eu tive que carpir na beira da estrada, onde o trator passa. $[\ldots]$ eu saio de casa às cinco e meia da manhã. O ônibus passa as dez pras seis pra ir pro campo. Chego lá às sete horas da manhã, aí eu como uma marmitinha. Aí você come um pouco de manhã, e um pouco meio dia. E vai carpindo, [...]. Tem mil e duzentos metros. Você leva a marmita pra comer, e não dá tempo nem pra mastigar. A garganta puxa sozinha. (E1)

É assim, chega às sete horas da manhã e vai até umas três horas da tarde. O fiscal quer que a gente trabalhe até as cinco [...]. Depois das três horas, seria hora extra, mas a gente nunca recebe por isso. Só cansa mais ainda. (E5)

Ah, tem também uma pausa de 10 minutos... a cada duas horas. [...] E é obrigatório. E se você não parar, eles ficam de olho em você e depois você vai ficar três dias em casa, vai tomar suspensão... Por quê? Acho que eles estão fazendo o melhor pra gente. (E14)

Alessi e Navarro (1997) descrevem como o processo de trabalho no corte da cana envolve um con- junto de atividades extenuantes, as quais são relatadas a seguir:

[...] atividades presentes desde o momento em que o cortador acorda para vestir-se, preparar suas refeições e providenciar seus instrumentos de trabalho, embarcando em caminhões, ônibus ou tratores, ou caminhar até a lavoura. [...] onde as condições presentes nos ambientes de trabalho são insalubres e perigosas. Manifestam-se normalmente em temperatura elevada, que se acentua no decorrer da jornada, com mudanças bruscas desta temperatura, [...] utilizando roupas sobrepostas, saias sobre calças compridas, camisas de mangas compridas, luvas improvisadas com meias e lenços cobrindo os rostos e a cabeça sob chapéus ou bonés. Levantar as 4 e 5 horas da manhã faz com que alguns trabalhadores almocem assim que chegam na lavoura, ou então por volta das 11 horas. [...] O corte na base da cana exige do trabalhador uma seqüência ritmada de movimentos corporais. Com um dos braços, o trabalhador abraça o maior número possível de colmos de cana. Em seguida, curva-se para frente e, com o podão seguro por uma de suas mãos, golpeia com um ou mais movimentos a base o mais próximo possível do solo. Em seguida, faz um movimento de rotação e levanta o feixe de cana já cortado, depositando-o em montes atrás de si. [...] Durante toda a jornada, o trabalhador repetirá exaustivamente os mesmos gestos. Tais movimentos, podem levar o trabalhador a diminuir seu limiar de atenção, aumentando a possibilidade de acidentes com o próprio podão. (ALESSI; NAVARRO, 1997, p. 10-11)

Dados do Instituto de Economia Agrícola - IEA (2008) demonstram que, no estado de São Paulo, a quantidade média de cana-de-açúcar colhida por trabalhador aumentou consideravelmente nos últimos anos, chegando à máxima de 18 toneladas ao dia nos anos de 2004 e 2005.

Entre 1970 e 2000, a quantidade média de cana-de-açúcar colhida por trabalhador aumentou de três para oito toneladas ao dia. Segundo Alessi e Scopinho (1994), o desempenho do cortador de cana masculino na década de 1990 alcançava 14 toneladas ao dia. Scopinho (2003) descreveu alguns dos efeitos advindos da superexploração do trabalhador:

[...] os cortadores de cana apresentam quadros patológicos compostos por doenças como dispnéia, dores lombares e torácicas, câimbras, comprometimentos da coluna vertebral (que se desdobra em incapacidade física), desidratação, oscilações da pressão arterial, problemas gastrointestinais, infecções respiratórias, dermatites, conjuntivites, envenenamento por picadas de animais peçonhentos e agrotóxicos, acidentes de trabalho e de trajeto, entre outras. [...] este padrão de adoecimentos apresenta estreita relação com o modo de organização e realização do trabalho na lavoura canavieira. (SCOPINHO 2003, p. 49)

\footnotetext{
5 “Carga laboral representa o conjunto de esforços desenvolvidos para atender às exigências das tarefas. Esse conceito abrange os esforços físicos, os cognitivos e os psicoafetivos (emocionais). [...] Como a carga de trabalho implica intensidade e portanto, quantificação, um imenso desafio é colocado quando se trata da dimensão subjetiva." (SELIGMANN-SILVA, 1994, p. 58)
} 
Alves (2006) afirmou que um trabalhador que corta 12 toneladas de cana ao dia, ao final do dia, terá caminhado mais de oito mil metros, despendido mais de 133 mil golpes com o facão e perdido cerca de oito litros de água em razão do esforço físico e do forte calor da exposição ao sol, tendo ainda que transportar os vários feixes cortados para a linha central. Todo este dispêndio de energia andando, golpeando, contorcendo-se, flexionando-se e carregando peso faz com que esses trabalhadores suem abundantemente, ao que o pesquisador complementa:

A perda de água e sais minerais leva à desidratação e à freqüente ocorrência de cãibras, que começam em geral pelas mãos e os pés, avançam pelas pernas, chegando ao tórax, acometendo todo o corpo, causando o que os trabalhadores denominam "birola". Essa cãibra provoca muita dor e paralisia total do trabalhador, semelhante a um ataque nervoso. Para conter as cãibras, as desidratações e a "birola", algumas usinas já levam para o campo e ministram aos trabalhadores soro fisiológico e suplementos energéticos, para reposição de sais minerais. Em outros casos, são os próprios trabalhadores que dirigem-se aos hospitais onde lhes é ministrado soro diretamente na veia. (ALVES, 2007, p. 34)

Tamanho esforço passa a exigir cada vez mais disposição e resistência física dos trabalhadores para poderem suportar essas atividades até o final da safra, o que leva ao crescente número de contratação de trabalhadores mais jovens, especialmente migrantes do interior do país, conforme pode-se constatar nesta pesquisa, bem como em outras bibliografias (SILVA, 1999; ALVES, 2007). Não obstante, as condições precárias de alimentação e moradia desses trabalhadores refletem-se diretamente em sua saúde.

De acordo com Silva (1999), doenças no aparelho respiratório são comumente constatadas entre os cortadores devido ao contato direto com a fuligem da queimada da cana. Tais condições de saúde e trabalho acabam por determinar as condições de vida desses cortadores, com corpos doentes e relativamente jovens.

Segundo a Pastoral do Migrante de Guariba, o pagamento dos cortadores de cana é feito com base na quantidade de cana cortada por dia de trabalho (FACIOLI; PERES, 2007). De acordo com Alves (2007), além do aumento da produtividade do trabalho, houve também redução brutal dos salários pagos aos trabalhadores do corte da cana. Segundo o mesmo autor, o aumento da produtividade e a redução da remuneração foram diretamente influenciados pelos seguintes fatores:

a) aumento da quantidade de trabalhadores disponíveis para ao corte da cana decorrente do desemprego geral, da economia, da mecanização do corte da cana e da expansão da fronteira agrícola para as regiões do cerrado; b) seleção dos trabalhadores pelas diretorias de Recursos Humanos das usinas - contrato por tempo determinado ou por tempo de safra;

c) redução da capacidade de organização e luta dos sindicatos dos trabalhadores rurais;

d) crescimento da terceirização destes trabalhadores.

A forma de remuneração por produção, acompanhada da queda dos valores pagos aos cortadores na região de Ribeirão Preto remete esses trabalhadores ao grau máximo de esforço físico para o desempenho de seu trabalho, almejando, desta forma, o recebimento de uma média de dois salários mínimos ao mês.

Cabe aqui registrar a ocorrência de mortes envolvendo cortadores de cana no momento da realização de seu trabalho, fato que pode estar diretamente relacionado à sua sobrecarga laboral. Desde 2004, a Pastoral do Migrante de Guariba tem recebido informações sobre mortes envolvendo migrantes empregados nas usinas do interior paulista. Entre 2004 e 2009, foram registradas 23 mortes de trabalhadores com idades entre 20 e 53 anos no exercício de seu trabalho. (FACIOLI; PERES, 2007).

A partir de tais denúncias, audiências públicas foram realizadas com o intuito de investigar estes fenômenos. A primeira delas ocorreu na Faculdade de Filosofia, Ciências e Letras de Ribeirão Preto, da Universidade de São Paulo, em que foram abrangidas questões relacionadas às mortes inexplicadas de trabalhadores rurais no setor de cana-de-açúcar, especialmente por tratar-se de pessoas de pouca idade para os casos identificados como parada respiratória. Também se discutiu as condições do trabalhador nesse setor e a necessidade de melhorias na fiscalização e na notificação das doenças laborais (MANCUSO, 2005).

O roubo das energias físicas do trabalhador devido à intensificação e ao prolongamento da jornada de trabalho ao longo dos anos não apenas dilapida sua saúde, como implica também no encurtamento do seu tempo de vida (NAVARRO, 2006).

Em seu segundo dia, E1 já demonstrava sinais aparentes de bastante cansaço e preocupação com o trabalho. Foi mencionado que a usina lhes fornece uma certa quantidade de pacotes de repositores de sais minerais para serem diluídos em água e consumidos em razão dos líquidos perdidos durante a execução do trabalho. Um dos entrevistados (E12) apresentou a embalagem de um repositor energético para atletas. Os demais entrevistados confirmaram a utilização para fins de reposição mineral, afirmado como um benefício dado pela usina:

O segundo dia meu foi hoje, e só tive que carpir o mato [...] porque senão eu teria desmaiado lá no meio da cana. Pro cansaço, dão um pacotinho de suco, todo dia [...] Hoje, chegar em casa, foi como chegar no céu. (E1) 
Tem um sorinho que eles dão na usina. Eles dão, mas não é pra cortar mais não, é pra não se cansar. Quando você força muito você pode ter câimbra. Aí [o soro] dá energia. Você toma ele ao meio-dia, é só por na água, desmanchar e tomar, não dá câimbra no corpo, você consegue trabalhar todo dia. (E12)

Outro dado bastante preocupante foi a utilização dos banheiros. Apesar da existência de cabines sanitárias no campo, muitos trabalhadores fazem suas necessidades a céu aberto, em áreas onde não há cana, apenas mato.

Pra ir ao banheiro, pode sair, você não precisa pedir não. Mas é no meio do mato. Porque até tem lugar que tem casinha... mas a gente deixa pras mulher usar. (E1)

O transporte até os canaviais era realizado por ônibus que, segundo os trabalhadores entrevistados, possuía condições bastante precárias de manutenção. Acidentes com transporte de cortadores de cana são periodicamente noticiados pela rede de telejornalismo local. Em uma das visitas à cidade de Pradópolis (SP), um dos entrevistados comentou sobre três cortadores de cana que haviam sido despedidos pela usina naquela tarde, antes mesmo de completarem os três meses de trabalho, por terem discutido com o encarregado de produção, reclamando das condições do ônibus que os conduzia para a usina.

\begin{abstract}
Nós saíamos daqui às quatro horas da manhã, e no meio do caminho o ônibus quebrava. Tinha que esperar que o outro viesse buscar, então chegava no serviço meio-dia. Aí já não compensava não. Disseram que ia mudar de ônibus, a gente até falou com o chefe da usina. O ônibus não acendia o farol, não tinha freio. Inclusive os que reclamaram ficaram marcados e foram até mandados embora por causa disso. Então, quando chegou lá no canavial, o dono da turma tratou a gente com ignorância. Quando a gente disse que não ia subir no ônibus sem freio, ele disse que a gente não queria trabalhar. Ele disse que, se a gente quisesse andar de ônibus bom, que fosse fazer turismo. (E8)
\end{abstract}

Um dos trabalhadores demitidos confirmou as informações e, com bastante insatisfação, comentou o quão difícil era a situação, não apenas por perder o emprego, mas, principalmente, por voltar para sua terra natal antes do término da safra sem poder levar aos seus familiares o dinheiro que esperava ganhar com o trabalho na colheita da cana.

\section{Pagamento por produção}

O pagamento do trabalho no corte da cana, como vimos, é feito por produção, ou seja, de acordo com a quantidade de cana cortada pelo trabalhador. Ao final da safra, ao fazerem o desligamento de seus empregados, as usinas devem efetuar o pagamento do acerto, no qual são calculados os valores do décimo terceiro salário, das férias e do fundo de ga- rantia proporcionais ao período trabalhado. Muitos trabalhadores contam com esta rescisão contratual para receber tal valor, que utilizarão para a compra da passagem de retorno à sua terra, levando consigo parte deste dinheiro, inclusive para sua manutenção nas entressafras. Daí a importância de permanecer até o fim da safra, pois retornar antes de seu término significa não ter a quantia de dinheiro prevista para levar para casa, além deste fato poder ser encarado como fracasso do trabalhador:

\begin{abstract}
Mas ele [o cortador] tem que atingir no mínimo um salário base, que é de quinhentos e vinte e cinco reais. Se o cara não atinge aquele salário, a usina não quer ele de jeito nenhum, porque o Ministério do Trabalho e o sindicato obriga a usina a pagar o piso. Aí se o cabra não atinge aquela metragem, ela [a usina] tem que cumprir pra ele. Se a cana é boa é mais barato, se for mais ruim é mais caro. Tem cana de cinqüenta centavos, tem cana de trinta centavos, tem cana de doze centavos o metro. Quando ela é cortada queimada é mais barato, quando é cortada na palha é mais caro. [...] Recebe um cheque de quinhentos, seiscentos reais a cada quinze dias. E no final da safra tem um acerto pra ti, que depende da tua produção. (E9)
\end{abstract}

Mas nem todos os trabalhadores conhecem os preços a serem pagos pela cana cortada. Confiam sua produção ao encarregado de turma, que é responsável pela coleta e pela pesagem: Pra falar a verdade, nós não sabemos nem o preço da
cana, porque a gente, quando trabalha lá, só tem que
saber cortar a cana. Um cara bem esforçado mesmo
ganha um troquinho a mais. Só que o que adianta, o
cara se esforça, se arrebenta todo, e aí vai fazer o que
da vida? (E5)

Eu sou um pequeno produtor no corte, todo mês eu tiro uns setecentos reais. Mas tem gente que tira em torno de oitocentos a mil reais. (E12)

Alves (2006) traz uma crítica a esta forma de pagamento por produção no corte da cana que apresenta exatamente a realidade retratada pelos trabalhadores entrevistados, mostrando como trabalham no corte de cana por produção, em pleno século XXI, sem saberem quanto ganham, visto que isto depende do quanto cortam. Além disso, mesmo cortando muitos metros, podem ter um ganho pequeno, porque o valor do metro depende de uma conversão que não é controlada pelos trabalhadores, mas sim pelas usinas (ALVES, 2006).

\section{Reflexos na saúde}

O grau de fragilidade e desamparo dos trabalhadores aqui apresentado também pode ser percebido na clara relação entre jornada de trabalho e ausência do convívio familiar. De acordo com Seligmann-Silva (1994), a qualidade do relacionamento do indivíduo com seus familiares é diretamente afetada pela es- 
trutura temporal do trabalho, pois quanto maior a jornada de trabalho, menor a convivência familiar e, consequentemente, maiores os desgastes físico e mental. Para o trabalhador rural e migrante, este desgaste se torna ainda maior no que tange não somente ao distanciamento familiar, mas também ao dilaceramento de sua cidadania através do trabalho itinerante e sobrecarregado, fenômenos que fraturam a identidade e o projeto de vida, com reflexos profundos na vida psíquica e na sociabilidade desses jovens trabalhadores.

As queixas mais frequentes apresentadas nos depoimentos (descritas na Tabela 2) foram de dores musculares, dores na coluna vertebral, insolação, desidratação, dores de cabeça, inchaços nos braços, câimbras e tremores:

Passei mal. Já tive dor na cabeça, com febre, por estar muito cansado, porque força muito. [...] Morre gente disso. Já ouvi meu irmão falar que viu gente que morreu abraçado com um monte de cana, morreu. (E2)

[...] Coloquei as roupas no varal e fui descansar a batata da perna, os pés, a coxa, o braço, porque dói tudo. Outro dia mesmo, tinha um que tava gritando lá, gritando, falando que ia morrer. Já chegou lá vomitando, vomitava sangue... E teve um outro que foi entrar no banheiro pra tomar banho e desmaiou. [...] Eu só tive câimbra nos primeiros dias, fechava a mão com o cabo do facão e não conseguia abrir [...] (E1)

Tive problema assim, na coluna, uma dor nas costas, aí para e toma um remédio lá. É o município mesmo que dá o remédio no posto. (E11)

Percebe-se aqui um esgotamento das forças e os sinais de desgastes físicos, que, pouco a pouco, sucateiam seus corpos, levando lentamente as suas energias para serem colhidas juntamente com a cana que cultivam.

Segundo Silva (2007), o grande esforço físico exigido neste tipo de atividade tem sérias implicações para a saúde destes trabalhadores. É comum a ocorrência de câimbras, dores lombares, comprometimentos da coluna vertebral e tendinites. Seligmann-Silva (1994) demonstra como a fraqueza e o cansaço físicos estão diretamente relacionados ao cansaço mental:

\begin{abstract}
A fadiga mental é indissociável da fadiga física. [...] Nos casos em que o cansaço se acumula ao longo do tempo, surgem os quadros que tem sido designados como fadiga crônica ou fadiga patológica, marcada não apenas pelo cansaço que não cede ao sono diário, mas também pelos distúrbios do sono, pela irritabilidade, pelo desânimo e às vezes, por dores diversas e perdas de apetite. Esse desgaste, passando pela dimensão corpórea, se faz desgaste aferível em termos de danos orgânicos, além de conter o sofrimento mental de inúmeras perdas. [...] quanto maior o cansaço, menor a possibilidade de participação social e lazer ativo significativo. Deste modo, o cansaço se faz ponte importante para a intensificação de uma sujeição que, muitas vezes, é a véspera da alienação. (SELIGMANN-SILVA, 1994, p. 80)
\end{abstract}

Lacaz (2007) destaca a importância, para os estudos que focam a questão da saúde do trabalhador, de se desvendar a nocividade do processo de trabalho sob o capitalismo e suas implicações, tais como a:

[...] alienação; sobrecarga e/ou subcarga; pela interação dinâmica de 'cargas' sobre os corpos que trabalham, conformando um nexo impeditivo da fluição das potencialidades e da criatividade. (p. 761)

Tabela 2 Categorias temáticas das verbalizações dos trabalhadores migrantes $(\mathrm{N}=14)$ empregados nas lavouras de cana-de-açúcar na cidade de Pradópolis (SP) que expressam suas condições de saúde, 2008-2009

\begin{tabular}{lc}
\hline \multicolumn{1}{c}{ Categorias } & Número de respostas \\
\hline Dores musculares / membros & 11 \\
Dores na coluna & 8 \\
Dores de cabeça & 4 \\
Câimbras & 3 \\
Cansaço excessivo & 12 \\
Não apresenta queixas & 2 \\
\hline
\end{tabular}




\section{Impressões, sentimentos e expectativas}

Após alguns meses de trabalho realizado nos canaviais pelos entrevistados, os relatos por eles apresentados demonstraram suas impressões e expectativas (ou a ausência delas) sobre a atividade em questão (conforme descriminados na Tabela 3). Em seus depoimentos, fica expresso que a migração em busca de trabalho não é uma opção para estes jovens, mas sim algo compulsório. É a única alternativa frente à realidade encontrada na região de origem. Estes depoimentos revelam também a desesperança destes jovens quanto às suas perspectivas de futuro e demonstram preocupação com as possíveis consequências para sua saúde (opinião expressa por 12 dos entrevistados).

Em razão do distanciamento de seu meio social e familiar, todos os trabalhadores entrevistados mencionaram o sentimento de saudade, outros confessaram a existência de alguns momentos de solidão, com ênfase para os que apresentaram problemas de saúde neste período. Apesar do desapontamento com esta realidade, 11 dos entrevistados têm intenção de retorno para as lavouras da cana nas próximas safras, em virtude da falta de oportunidades em sua região, surgindo também o conformismo com sua realidade social (de acordo com nove entrevistados). E, finalmente, sendo mencionado também em nove depoimentos, o sentimento de frustração quando percebido que o tipo de trabalho real era bem diferente do imaginado anteriormente:

O cara trabalha até quase morrer. Por isso que me poupo, não é que eu não quero trabalhar, coragem eu tenho, mas eu nunca vou fazer isso na minha vida, porque eu sei que eu não resisto. Não adianta eu querer fazer o que eu não posso. (E12)

[...] Desse jeito não. Eu prefiro trabalhar cinco anos plantando feijão e milho do que um ano cortando cana. Serviço melhor eu não vou achar, porque eu não tenho estudo pra isso. Não acha, não. (E1)
Vamos supor, com os meus estudos... Lá [no Maranhão] eles vivem de quê? Não tem porque eu querer me formar pra medicina, onde é que eu vou entrar lá? Não tem pra onde entrar lá. O cara vai terminar os estudos lá pra vir cortar aqui? Não adianta nada... Eu quero ficar aqui até 2010. Eu pretendo... (E5)

Olha, quando eu comecei era cansativo, eu entrei em desespero. A hora que eu cheguei aqui na primeira vez, eu falei: "Misericórdia, isso aqui é um horror", mas, graças a Deus, eu fui tendo forças, porque quando você tá no canavial, você sabe que quanto mais você faz mais você pode ganhar. Ali, é só fazendo mesmo. (E14)

Este é o quarto ano do meu amigo. Já levou até moto, comprou muita coisa pra dentro de casa, entendeu. $\mathrm{E}$ eu volto de mãos vazias. (E7)

Os depoimentos revelam ainda como esse tipo de trabalho permanece árduo, intenso, insalubre e desumano. Do trabalhador se exige, além de destreza para manusear o facão, muita força física, disposição para enfrentar as agruras de uma região desconhecida, com contrastes climáticos e as precárias condições de moradia. Agrava o quadro o pouco tempo livre para descanso. Ficam também explícitas suas expectativas em relação a um tipo diferente de trabalho, alternativo ao trabalho assalariado no corte da cana:

Eu nunca mais! O frio das três da manhã, e o calor do meio dia. Lá onde eu moro é quente, mas aqui é diferente. Eu quero cuidar de roça, se um dia eu voltar pra cá, mas pra cortar cana eu não quero não, é ruim demais... Tenho uns amigos que trabalham lá em São Paulo, vou ver se consigo um emprego por lá... (E8)

Ah... eu até vou continuar com a cana mais um tempo. Mas o único serviço que é o meu sonho... O meu sonho mesmo é cuidar de porco. Porque eu tenho amor ao negócio de porco. Posso capar, limpar chiqueiro, tirar filhote, tratar igual a um pato, dá até pra brincar, segurar pra lá, pra cá. Se tiver que segurar pra capar também, eu seguro. Mas é disso mesmo que eu tenho vontade. Porque meu estudo não dá pra outra coisa. [...] Um dia eu vou achar uma granja de porco pra eu cuidar, pra eu tomar conta deles. (E1)

Tabela 3 Categorias temáticas das verbalizações dos trabalhadores migrantes $(\mathrm{N}=14)$ empregados nas lavouras de cana-de-açúcar na cidade de Pradópolis (SP) que expressam suas percepções, seus sentimentos e suas expectativas, 2008-2009

\begin{tabular}{lc}
\hline \multicolumn{1}{c}{ Categorias } & Número de respostas \\
\hline Preocupação quanto à saúde & 12 \\
Desapontamento com o trabalho nos canaviais & 4 \\
Saudade dos familiares e amigos & 14 \\
Intenção de retorno na próxima safra & 10 \\
Conformismo / Falta de perspectivas de melhorias & 9 \\
Frustração & 9 \\
\hline
\end{tabular}


Rapaz... Deus me livre de cortar cana pra sempre. [...] Eu tenho um plano na minha cabeça assim, de comprar pelo menos umas duas mesas de bilhar, e quando eu chegar lá, no fim do ano, deixar uma lá em casa, e alugar a outra. Dá um dinheiro bom. (E5)

A decisão pela permanência ou não no corte da cana será decorrente de todas as questões estruturais anteriormente apresentadas, que vão desde as razões que impulsionaram a migração destes trabalhadores aos primeiros sinais de desgaste de sua saúde, associados ao sofrimento psíquico, que possivelmente decorrem dos sentimentos de impotência e distanciamento de seus familiares e da terra natal.

De acordo com a bibliografia específica sobre a migração (VETTORASSI, 2010; SILVA, 1999), há alguns fatores que esclarecem o alto número de trabalhadores migrantes no corte manual de cana. O mais importante deles diz respeito ao valor da força de trabalho. É sabido que a força de trabalho migrante é mais barata e mais suscetível a condições degradantes de trabalho porque suas condições de vida e acesso a empregos dignos são mais precários. Além disso, há uma série de contatos feitos por agenciadores de trabalho "migrante". Esta malha de contatos constituída por empregadores, agenciadores, companhias de ônibus e até mesmo famílias migrantes que já vivem no interior paulista forma o que Vettorassi (2010) intitula como "redes sociais", que funcionam exclusivamente para a busca de nova mão de obra suscetível a piores condições de trabalho e que sustenta não apenas as usinas canavieiras, mas outros grupos e instituições que se beneficiam dela. Assim, o migrante está longe de sua zona de conforto, influenciado pelas redes sociais que agenciam seu trabalho e, consequentemente, mais vulnerável às condições de trabalho que lhe são ofertadas, mesmo que degradantes.

Dessa forma, nota-se que, enquanto uma parcela (em expansão) sofre com o desemprego e com a falta de colocação no mercado de trabalho, outra, que continua empregada, padece de males consequentes do excesso e da sobrecarga de trabalho que lhe são impostos. A explicação para este problema pode ser buscada nessas mudanças ocorridas no mundo do trabalho nas últimas décadas, que trouxeram como traço marcante, por um lado, uma fantástica inovação tecnológica e, por outro, uma intensificação da exploração da força de trabalho, através do aumento de jornada, do ritmo, de contratos precários, da diminuição do tempo livre e do crescimento do desemprego (NAVARRO, 2006).

\section{Considerações finais}

Os dados obtidos corroboram dados de estudos anteriores que revelam a árdua rotina de trabalho vivenciada pelos migrantes do corte da cana que iniciam seu dia entre quatro e cinco horas da manhã e apenas cessam suas atividades de trabalho por volta das onze horas da noite.

Ficou evidente, a partir dos depoimentos colhidos e da bibliografia selecionada, que as jornadas de trabalho na colheita manual da cana de açúcar permanecem extensivas, há intensificação do ritmo, exigência do cumprimento de metas de produção, que o transporte é inadequado e inseguro, que as moradias são precárias e abrigam número elevado de trabalhadores, o que aumenta o desconforto e a precariedade das condições de higiene.

A remuneração por produção, um dos mais perversos mecanismos de exploração desses trabalhadores, implica na intensificação do ritmo de trabalho e no maior desgaste do trabalhador. A existência de metas de produção que estabelecem o corte de 10 a 12 toneladas de cana ao dia, além de estimular a competitividade entre os trabalhadores em benefício das usinas, é também maneira "eficiente" de selecionar os mais aptos a suportarem este tipo de trabalho.

Em virtude do desapontamento, do sentimento de frustração em relação ao trabalho, que se mostrou muito diferente do que era imaginado por eles, e do reconhecimento do quão penosa e prejudicial à sua saúde é esta atividade, parte dos entrevistados não tinha intenção de retornar para o trabalho nas lavouras da cana, porém, a falta de oportunidades de emprego que lhes possibilitem assegurar sua subsistência e de sua família faz com que retornem.

As queixas mais frequentemente relatadas quanto à saúde relacionadas ao trabalho foram dores musculares, dores na coluna vertebral, desidratação, dores de cabeça, inchaço nos braços, câimbras, tremores e sentimentos de desapontamento com a realidade do trabalho.

Os dados revelaram facetas de como ocorre a exploração da força de trabalho empregada na cultura da cana-de-açúcar na maior região produtora do país, com destaque para as questões relacionadas ao processo de migração, das condições de trabalho e da saúde dos trabalhadores.

Estudos como este, que reforçam e ampliam dados obtidos em outras pesquisas, são justificados pela gravidade da exploração dos trabalhadores envolvidos nesta atividade insalubre, penosa e desgastante. Ao se delimitar o estudo ao trabalho de jovens migrantes, esta pesquisa buscou contribuir para o conhecimento de sentimentos, expectativas e preocupações expressas por esses trabalhadores, aos quais o trabalho no corte da cana parece ser cada vez mais reservado. 


\section{Contribuições de autoria}

Galiano, A. de M.: responsável pelo delineamento do projeto, pelo levantamento de dados e pela sua análise e interpretação, bem como pela elaboração do manuscrito. Vetorassi, A.: contribuição substancial no projeto, no levantamento de dados e na sua análise e interpretação, além de sua essencial revisão crítica. Navarro, V. L.: contribuiu também com dados relevantes ao tema, em sua análise e interpretação, bem como na orientação, na revisão crítica do artigo e na aprovação de sua versão final.

\section{Referências}

ALESSI, N. P.; NAVARRO, V. L. O trabalho de crianças e adolescentes na cultura canavieira e os impactos sobre sua saúde. Informações Econômicas, v. 27, n. 6, p. 7-16, 1997.

ALESSI, N. P.; SCOPINHO, R. A. A saúde do trabalhador do corte de cana-de-açúcar. In: ALESSI, N. P. et al (Org.). Saúde e trabalho no Sistema Único de Saúde. São Paulo: Hucitec, 1994. p. 121-151.

ALVES, F. Porque morrem os cortadores de cana? Saúde e Sociedade, v. 15, n. 3, p. 9098, set./dez. 2006. Disponível em: http:// www.scielo.br/scielo.php?script $=$ sci_arttext\& pid $=$ S0104-12902006000300008 $>$. Ácesso em: 15 fev. 2009.

. Migração de trabalhadores rurais do Maranhão e Piauí para o corte de cana em São Paulo: será esse um fenômeno casual ou recorrente da estratégia empresarial do Complexo Agroindustrial Canavieiro? In: NOVAES, R.; ALVES, F. Migrantes: trabalho e trabalhadores no complexo agroindustrial canavieiro (os heróis do agronegócio brasileiro). São Carlos: EdUFSCar, 2007. p. 21-54.

ANTUNES, R. Os sentidos do trabalho: ensaio sobre a afirmação e a negação do trabalho. São Paulo: Boitempo Editorial, 1999.

BIANCO, B. F. (Org.) A antropologia das sociedades contemporâneas. São Paulo: Global. 1987.

BIERNARCKI, P.; WALDORF, D. Snowball samplingproblems and techniques of chain referral sampling. Sociological Methods and Research, v. 10, n. 2, p. 141-163, 1981.

FACIOLI, I.; PERES, G. Histórico de cortadores de cana mortos no setor canavieiro. Pastoral do Migrante, Guariba, 18 maio 2007. Disponível em: <http://www. pastoraldomigrante.org.br/index.php?option $=\mathrm{com}_{-}$ content\&view $=$ article\&id $=44$ :historico-doscortadores-de-cana-mortos-no-setor-canavieiro\&catid=47:memoria >. Acesso em: 13 jan. 2009.

INSTITUTO BRASILEIRO DE GEOGRAFIA E ESTATÍSTICA. Contagem da população 2007. Disponível em: <http://www.ibge.gov.br/home/ estatistica/populacao/contagem2007/default.shtm> Acesso em: 11 nov. 2009.
INSTITUTO DE ECONOMIA AGRÍCOLA. Banco de dados. Disponível em: <http://www.iea.sp.gov.br>. Acesso em: 04 nov. 2008.

LACAZ, F. A. C. O campo saúde do trabalhador: resgatando conhecimentos e práticas sobre as relações trabalho-saúde. Cadernos de Saúde Pública, Rio de Janeiro, v. 23, n. 4, p. 757-766, abr. 2007.

MANCUSO, M. A. Exploração da mão-de-obra, condições de moradia e alimentação, submissão a esforço excessivo e à morte de trabalhadores rurais, lavoura de cana-de-açúcar, região de Ribeirão PretoSP. São Paulo: Ministério Público Federal, 2005. (Ata de Audiência Pública) Disponível em: http://www.prsp. mpf.gov.br/prdc/area-de-atuacao/escravtraf/Ata\%20 da\%20Audiencia\%20Publica\%20realizada\%20em\%20 Ribeirao\%20Preto\%20-\%20traba.pdf > . Acesso em: 02 out. 2008.

MINAYO, M. C. S. O desafio do conhecimento: pesquisa qualitativa em saúde. São Paulo: Hucitec; Abrasco, 1994.

NAVARRO, V. L. A indústria de calçados no turbilhão da reestruturação. In: ANTUNES, R. (Org.). Riqueza e miséria do trabalho no Brasil. São Paulo: Boitempo Editorial, 2006. p. 387-424.

NOVAES, J. R. P.; ALVES, F. Migrantes: trabalho e trabalhadores no complexo agroindustrial canavieiro (os heróis do agronegócio brasileiro). São Carlos: EdUFSCar, 2007.

POCHMANN, M. A batalha pelo primeiro emprego. São Paulo: Publisher Brasil, 2000.

ROSA, L. A. Trabalho e trabalhadores dos canaviais: perfil dos cortadores de cana da região de Ribeirão Preto (SP). 2009. XX f. Trabalho de Conculsão de Curso (Bacharel em Psicologia)-Programa de Bacharelado em Psicologia. Departamento de Psicologia e Educação. Faculdade de Filosofia, Ciências e Letras de Ribeirão Preto-USP, Ribeirão Preto, 2009.

SCOPINHO, R. A. Vigiando a vigilância: saúde e segurança no trabalho em tempos de qualidade total. São Paulo: Annablume; Fapesp, 2003.

SELIGMANN-SILVA, E. Desgaste mental no trabalho dominado. Rio de Janeiro: UFRJ; Cortez, 1994. 
SILVA, M. A. M. Errantes do fim do século. São Paulo: Fundação Editora da Unesp, 1999.

Se eu pudesse, eu quebraria todas as máquinas. Idéias - Revista do Instituto de Filosofia e Ciências Humanas, Campinas, ano 9/10, v. 2/1, p. 2564, 2002.

A morte ronda os canaviais paulistas. Revista da Associação Brasileira de Reforma Agrária, São Paulo, v. 33, n. 2, p. 111-144, ago./dez. 2006.

. Trabalho e trabalhadores na região do "mar de cana e do rio de álcool”. In: NOVAES, R.; ALVES, F. Migrantes: trabalho e trabalhadores no complexo agroindustrial canavieiro (os heróis do agronegócio brasileiro). São Carlos: EdUFSCar, 2007. p. 55-86.

THOMAZ JR., A. Por trás dos canaviais, os "nós” da cana: a relação capital x trabalho e o movimento sindical dos trabalhadores na agroindústria canavieira paulista. São Paulo: Annablume; Fapesp, 2002.

VETTORASSI, A. Laços de trabalho e redes dos migrantes: um estudo sobre as dimensões objetivas e subjetivas presentes em redes sociais e identidades de grupos migrantes de Serrana-SP e Guariba-SP. 2010. 213 f. Tese (Doutorado em Sociologia)-Instituto de Filosofia e Ciências Humanas, Unicamp, Campinas, 2010. 